\title{
Association of Respiratory Impairment with Use of Anti-cholinesterase Pesticides in Migrant Fruit Farm Workers in Eastern Thailand
}

\author{
Anamai Thetkathuek, Teerayuth Sa-ngiamsak, and Panuwat Choedkiattikool
}

\begin{abstract}
Migrant farm workers are exposed to occupational hazards in terms of exposure to pesticides containing organophosphate (OP) and carbamate (CM). In cases of mishandling of a pesticide, workers may be exposed to higher amounts of such toxic particles. Our study involved assessing factors related to respiratory disorders, including evidence of impaired lung function and respiratory system disorder symptoms (RSDS), in 274 migrant farm workers in Eastern Thailand. The experimental procedure involved interviews, as well as serum cholinesterase (SChE) and lung function assessments using a reactive paper blood test and spirometry, respectively. A multiple logistic regression analysis of independent variables and RSDS revealed an odds ratio (OR, $95 \%$ CI) of $2.787(1.210,6.470)$ in female subjects. Consumption of $>4$ glasses of alcohol/week and exposure to dust for $>4 \mathrm{~h} /$ day were associated with an OR $(95 \%$ CI $)$ of $4.675(1.395,15.671)$ and $2.743(1.238,6.093)$, respectively. The multiple linear regression analysis of independent variables indicated that the SChE level, gender, age, and carrying of a sprayer were associated with as determined from the forced vital capacity $(R$ $=0.579, \mathrm{R} 2=0.34 ; \mathrm{p}<0.05$ ) and additionally associated with the forced expired volume in one second $(R=0.562, R 2=0.315 ; p<$ 0.05). The assessment of respiratory system disorders is necessary for female farm workers who consume $>3$ glasses of alcohol/week, are older in age, and perform tasks that involve carrying a sprayer. Moreover, the SChE level should be routinely screened to monitor the health of migrant workers.
\end{abstract}

Index Terms-Migrant farm workers, cholinesterase level, respiratory impairment, lung function test, fruit farm, Thailand.

\section{INTRODUCTION}

Thailand is an agricultural country, with a total population of 65.7 million, according to the latest survey of National Statistical Office of Thailand [1]. Of the inhabitants, 14.8 million $(38.7 \%)$ are farm workers in the agricultural sector [2]. However, the number of farm workers has continuously decreased over the years, and the resulting gap has been filled by migrant labor [3]. Ministry of Labor reports conducted in 2011 and 2016 revealed an increasing trend in the number of migrant laborers, from 248,064 to $1,437,716$ [4]. Due to the

Manuscript received September 19, 2019; revised March 1, 2020. This work was supported by the research grant of Burapha University through National Research of Thailand (Grant No. 48/2017).

The authors are with the Department of Industrial hygiene and safety, Faculty of Public health, Burapha University, Chonburi 20131, Thailand (e-mail: anamai@buu.ac.th). close proximity of Eastern Thailand to the Cambodian-Thailand border, workers from Cambodia are usually employed in fruit plantations in this region, especially the Chanthaburi and Rayong provinces.

Migrant farm workers are exposed to occupational hazards, including exposure to pesticides containing organophosphate (OP) and carbamate (CM). In cases of pesticide mishandling, these workers may be exposed to higher amounts of such toxins. Moreover, these pesticides act by suppressing acetylcholinesterase (AChE), leading to adverse health effects, such as diverse alterations of the digestive, neurological, respiratory, circulatory, dermatological, renal, reproductive, and respiratory systems [5]-[10].

Exposure to pesticides containing OP and CM has been reported to cause muscarinic effects, leading to breathing difficulties, cough, runny nose, constriction of bronchial smooth muscles, chest tightness, wheeze, and bronchoconstriction [8]-[10]. In addition, exposure to pesticide spray is a potential asthma trigger [11]. These pesticides induce an increase in body fluid and cause severe impairment on oxygenation (hypoxemia), potentially resulting in cyanosis [9], [12] and deterioration of pulmonary competency. Several studies have shown that pesticide exposure is associated with decreased forced vital capacity (FVC), indicative of restrictive lung dysfunction [13], and decreased forced expired volume in $1 \mathrm{~s}$ (FEV1) [14]-[17].

Factors related to the symptoms of respiratory system distress include individual attributes such as gender. In this regard, women are more susceptible to respiratory disorders than men [18]-[20]. Also, aging is associated with pulmonary function deterioration [21], [22]. Negatu et al. [15] showed that patients with a history of alcohol consumption display higher levels of respiratory disorders than those who abstain from alcohol use. Work-related factors, such as lack of protective clothing, knowledge [23], direction while spraying pesticides, and safety measures against potential risks of pesticide exposure [24], can lead to higher risk of pesticide exposure [25] and alterations in AChE levels [26]. Typically, farmers either do not or incorrectly wear personal protective equipment, due to probable economic crisis, according to previous studies, which indicate a relationship between economic growth and poverty reduction in Indonesia before and after the Asian Financial Crisis [27]. Similarly, several studies have found that the general health of workers was affected by this crisis, increasing the risk of health disorders such as cardiovascular and respiratory diseases [28].

A study on Indian farm workers involved in spraying OPand CM-containing pesticides supports the association of 
reduced red blood cells and AChE with respiratory system disorders [16]. Hoppin and co-workers [11] reported that exposure to OP- and CM-containing pesticides leads to a greater occurrence of wheeze than non-exposure.

A recent investigation by Thetkathuek and co-workers [29] on the effects of these pesticides on Cambodian migrant farm workers showed that $64.9 \%$ workers displayed progressive neurodegenerative disorders and 58\% developed respiratory system distress symptoms. Therefore, a focused assessment of the respiratory system in this working group is crucial to prevent health complications.

Routine health risk assessments must be considered for protection of the health and safety of migrant laborers. Biological monitoring can combine exposure to and absorption from several routes into one measurement and may suggest the best technique to precisely assess an absorbed dose [13]. Biological exposure and effect biomarkers can be determined by the depression of plasma cholinesterase and erythrocyte cholinesterase (AChE) as a method for assessing exposure to OPs and CMs [30]-[32] as well as micronuclei assays and comet assays that reduce the blood cholinesterase level from OP pesticide exposure [33]. These techniques may also be used as a rapid method to screen the adverse health effects of OP/CM pesticide poisoning [34]. The EQM Test-Mate [17] and reactive paper test kits [35] are widely used to screen for the presence of $\mathrm{OP} / \mathrm{CM}$ pesticides [7].

The World Health Organization has declared that "health is a status of wellness of bodies and minds as well as sustaining of livelihood, and not merely the absence of illness and disability" [36]. Presently, a healthcare monitoring system for migrant workers has been established according to specifications of the Ministry of Public Health on the medical check-up and health assurance requirements for workers from Myanmar, Laos, and Cambodia. The services provided include annual medical check-ups, medical services, health promotion services, and disease control and monitoring [37]. Sutoluk et al. [38] have studied the relationship between serum cholinesterase (SChE) and pulmonary function. Their results show significantly decreased SChE levels in farm workers, but no association with lung function. In contrast, Peiris-John and colleagues [13] found lower levels of SChE and decreased pulmonary capacity, based on reduced FVC, FEV1, and FVC/FEV1 levels, in farm workers exposed to pesticides. Consistent with these findings, Pathak et al. [39] demonstrated that exposure to pesticides has a severe impact on the respiratory system, leading to deterioration of lung function $(p<0.05)$.

To the best of our knowledge, no studies have been conducted to date on pesticide-related respiratory disorders in migrant farm workers in Thailand. Therefore, we assess the respiratory system distress symptoms caused by exposure to pesticides by evaluating related factors and lung function in migrant farm workers. This assessment will help obtain essential laboratory data indicating the respiratory system health in this population. The collective measurements can be used for further assessments. It will also help develop effective guidelines to improve the healthcare and monitoring of the respiratory system in migrant farm workers exposed to OP- and CM-containing pesticides in Thailand.

\section{MethodOLOGY}

\section{A. Population}

A cross-sectional study was performed to assess disorders of the respiratory system and their associated factors in migrant farm workers. Typically, harvests, including those of rambutans, durians, mangosteens, longans, pineapples, and grapes, are performed biannually in Eastern Thailand. The first harvest is from April to May and the second is from June to July. In this study, we collected data from June to August 2017.

The researchers interviewed regarding the insecticides used by orchard owners. The following are the type of pesticides commonly used in fruit plantations: 1) those containing OP, such as omethoate, dimethodate, and chlorpyrifos; 2) those containing CM, such as methomyl and carbaryl; and 3) other chemicals, such as abamectin. The study sites were the Chanthaburi and Rayong provinces, where the fruit farms are located close to the Cambodian border.

\section{B. Sample Populations}

The study population comprised migrant farm workers from Cambodia, specifically permanent daily-paid employees in fruit farms in the Rayong and Chanthaburi provinces. The participants had worked for at least 6 months and used OP- and/or CM-containing pesticides. Additional permission for study participation was obtained from the participants' employers."

Migrant farm workers from randomly selected fruit farms were included in the study if they were Cambodian nationals involved as permanent daily-paid servants on a fruit farm and if they had been employed for at least 1 year. Additionally, acceptability was limited to workers with self-reported pesticide exposure whose employers reported OP- and/or CM-containing insecticide use on their fruit farm. All study subjects consented to participate with the protocol. An agreement to enroll study subjects from the farm workers was obtained from each employer in advance. All study subjects were permitted to refuse to participate or withdraw from the study at any time without consequences. Those who agreed to collaborate provided written informed consent.

The sample size used to screen for respiratory system disorders triggered by pesticide exposure in migrant farm workers of both genders registered as fruit farm workers in Eastern Thailand (Chanthaburi and Rayong provinces) was calculated via a simple logistic regression analysis. After the calculation of $n$, the sample size was adjusted according to the variables, where $n p$ was the adjusted size of the sample, n1 was the sample size calculated using the formula for a simple logistic regression analysis, and R2 was the correlation coefficient of multiple logistic regression at $25 \%$ $(\mathrm{R} 2=0.25)[40]$. The adjusted sample size was 263 participants.

\section{Research Ethics}

All subjects were allowed to withdraw from the study, with no consequences. The subjects were endorsed by the Institutional Review Board of Burapha University, which reviewed and approved this project. 


\section{Data Tools and Collection}

The data collection tools used included questionnaires, blood sampling, and diagnosis of lung function.

1) The questionnaires used in this study were translated into the Khmer language and subdivided into five sections with a total of 33 questions.

Part 1: social and demographic characteristics, including gender, age, marital status, educational background, and income.

Part 2: past and current tobacco use, including duration of smoking (years) and number of cigarettes smoked per day; past and current alcohol consumption; and the amount of alcohol consumed per dayl.

Part 3: history of illness (past and current illnesses), including any ailments in the past 6 months, severity of illness, and diagnosis of respiratory diseases by medical practitioners.

Part 4: work history, including current work information, previous career before working at the fruit farm, work duration, current tasks on the fruit farm, type of fruits (rambutan, durian, mangosteen, longan, pineapple, and grape), duration of work requiring the use of agricultural pesticides (year), total area of the plantation $(1 \mathrm{rai}=0.16$ acres), knowledge of the type of pesticide used in the most recent session, guidelines on pesticide safety provided by the employer or officer, number of spraying sessions (per week), pesticide spray duration (hours), pesticide spraying method, number of days since the last spraying session, and history of dust exposure.

Part 5: the use of personal preventive equipment and clothing, such as eyeglasses/masks to cover the nose, gloves, boots, long-sleeved shirts, long pants, or a gown to cover the body.

Part 6: respiratory system disorder symptoms (RSDS). The questions were adapted from the British Medical Research Council [41] regarding information on cough, phlegm production, chest tightness, and chest pain symptoms Interpreted results were classified as either zero (normal) or one (disorders including the above symptoms).

2) Assessment of exposure to OP- and CM-containing pesticides.

Reactive paper is a paper-based sensor used for the simple and rapid screening of OP and CM pesticides based on the inhibition of AChE in serum. This enzyme degrades the neurotransmitter acetylcholine. On exposure, OP- or CM-containing pesticides accumulate and suppress the cholinesterase activity. Therefore, SChE enzyme levels and associated hazardous effects should be routinely monitored in those exposed to such pesticides [42].

The equipment used to collect blood samples included alcohol (70\%), clean cotton, gloves, rubber bands, pincers, clay trays, Propipet, plastic vacuum tube needle set, a red-tipped tube, and reactive paper (cholinesterase paper) together with a standard color indicator. The blood samples were securely collected in a dry bottle at a temperature of $4^{\circ}-80^{\circ}$ and incubated in a refrigerator during field trips. The reactive paper (purchased from the Governmental Pharmaceutical Organization) was incubated in an ice box without exposure to sunlight.

The blood samples were examined for SChE activity via a reactive paper test kit provided by the Government Pharmaceutical Organization of Thailand. Husbumrer et al.'s [43] colorimetric strip method of qualitative testing for cholinesterase using a reactive paper is a simple and effective method for the early screening of OP- and CM-containing pesticides.

Reactive papers are made of cellulose filter paper dipped in bromothymol blue (a color indicator) and ACh chloride (a cholinesterase substrate). Determination of cholinesterase activity at $25^{\circ} \pm 10^{\circ}$ and $70 \%$ relative humidity can be completed within $7 \mathrm{~min}$. In this study, the cholinesterase activities determined via the Bigg's and reactive paper methods were not significantly different, with a correlation coefficient of 0.56 within a cholinesterase activity range of 20-120 U/mL. The reactive paper and test kits were supplied by the Bureau of Occupational and Environmental Diseases, Department of Disease Control, Ministry of Public Health, Thailand [42].

3) This study used two Datospir-120 P/N 511-800-Mu 2 spirometers with minimum accuracy and precision settings according to the American Thoracic Society's 1994 guidelines for spirometry [44], [45].

\section{E. Quality Assessment of the Research Tools}

The quality assessment of the research tools used was divided into two sections: validation with questionnaires and lung function equipment analysis. The first section of the assessment included questionnaires generated by qualified individuals. Reviewers in the field of occupational health evaluated the questionnaires' accuracy of structure, registering of verbal expression, and contents and coverage. These qualified individuals comprised a medical doctor specializing in occupational medicine and a lecturer dealing with occupational health and safety. The validity of the equipment used to examine lung function was verified (calibration) before use at the research site.

\section{F. Data Collection}

The data collection was subdivided into the following stages:

\section{1) Interview}

The interview questionnaire was converted and rewritten from Thai into Khmer and accounted to interview migrant workers via a translator and researcher. The interview questions were classified into six parts, with a total of 33 questions. Before the researchers went to collect data in the fruit farms, an information and request letter was sent to the employers and the director of Health Promoting Hospital. Interviews were performed in the presence of a translator. The translator and the Thai interviewers/researchers were trained before data collection started. The migrant workers were interviewed by a Khmer-speaking interpreter and a Thai researcher together on the day off of their work shift. Each interview took an average of $15 \mathrm{~min}$ at the Tambol Health Promoting Hospital.

2) Assessment of exposure to pesticides via blood sampling

After the collection of interview-based information, the researcher assessed the level of pesticide exposure via blood sampling by using a reactive paper. The procedure involved the following steps: 1) taking blood samples obtained from the first stage into capillary tubes, 2) waiting until a layer 
separating the plasma and red blood cells appeared, 3) using the reactive paper designed to assess toxicity of the pesticide on the slide, 4) putting a drop of lymph from Stage 3 samples on the reactive paper, 5) covering the paper with another slide, 6) waiting for $7 \mathrm{~min}$, and 7) determining the result by comparing the color change based on a standard indicator.

The results were interpreted based on four colors: yellow, $\geq 100 \mathrm{U} / \mathrm{mL}$ (normal); yellow-green, 87.5-99.9 U/mL (safe); green, 75.0-87.4 U/mL (at risk); blue, $<75.0 \mathrm{U} / \mathrm{mL}$ (unsafe). The statistical analysis was based on two groups: normal (yellow and yellow-green) and abnormal (green and blue).

3) Lung function assessment

The duration of the interview and lung function test was 10 min per participant. This procedure was conducted by well-trained occupational hygiene practitioners. Before the pulmonary assessment, the calibration protocol was performed, and the assessment method was explained and demonstrated to the target group, to ensure the participants fully understood the procedure. The lung function test required each subject to be able to use the spirometer for data interpretation and sit in a specific posture as indicated by the Association of Occupational and Environmental Diseases of Thailand [45], i.e., upright and looking straight forward. Both feet had to touch the floor, with the nose closer applied and the mouthpiece securely positioned. Each subject had to inhale as fast as possible for at least $1 \mathrm{~s}$ and, then, exhale as rapidly as possible (letting all the air out). The procedure had to be repeated at least three times. At least two trials had to be within $5 \%$ of each other. All three attempts were analyzed, and the results are presented in a graph. In cases in which a subject became highly exhausted, the test was discontinued. Data recording and analysis constituted the final steps.

The interpretation of the lung function assessment data complied with the Siriraj equation. To indicate whether pulmonary competency was normal, the results were compared with the sprirometric reference equations established in 2002 by the Thoracic Society of Thailand under Royal Patronage [44].

The criteria for the lung function test were categorized based on the percentage predicted FVC (obstructive abnormalities) and percentage predicted FEV1/FVC (restrictive abnormalities). The normal scale was $>80$, and the abnormal scale was categorized as mild, moderate, and severe $(66-80,50-65$, and $<50)$, respectively.

\section{G. Data Analysis}

The statistical analysis was conducted using the SPSS/PC software and subdivided into two sections:

1) Descriptive analysis comprised the lung function test and RSDS assessment. In the analysis, the information was tabulated and the frequency, percentage, average score, and standard deviation were used to explain general variables, such as sociodemographic characteristics, history of tobacco use, alcohol consumption, illness history, work history, use of personal preventive equipment, and RSDS of migrant workers in fruit farms in Eastern Thailand.

2) Analysis of factors associated with respiratory system disorders: (2.1) Multivariable logistic regression analysis: independent variables, including gender, age, past and current tobacco use (not using/using), frequency of alcohol consumption (time/week), soil dust exposure history, cholinesterase level, and $\mathrm{FEV}_{1} / \mathrm{FVC}$ results, and dependent variables, including RSDS. The RSDS were cough, phlegm, chest tightness, difficulty breathing, and chest pain. The results were categorized as zero (normal) or one (disorder). (2.2) Multiple linear regression analysis: independent variables, including gender, age, educational background, current tobacco use, current alcohol consumption, pesticide spraying tasks, pesticide spraying assistance, and cholinesterase level, and dependent variables, including FVC and $\mathrm{FEV}_{1}$ scores.

\section{FINDINGS}

Screening for RSDS triggered by exposure to pesticides was conducted to determine the contributory factors in 274 migrant farm workers in Eastern Thailand. The data collection was conducted via interviews along with assessment of lung function through spirometry and SChE levels using the reactive paper finger-blood test. The data were subsequently classified into 10 categories.

\section{A. Sociodemographic Characteristics and History of Tobacco and Alcohol Use}

Of the 274 migrant farmer workers exposed to pesticides, most were male $(60.6 \%)$ with an average age of 30.80 years $(\mathrm{SD}=9.46)$. The age range of the majority of male $(42.8 \%)$ and female $(41.7 \%)$ subjects was $21-30$ years. A large proportion of subjects had not received formal education (men, 31.9\%; women, 31.5\%). In terms of past tobacco use and current tobacco use, $53.0 \%$ male and $3.7 \%$ female farm workers had smoked cigarettes in the past, among whom $48.8 \%$ male and $2.8 \%$ female workers continued to smoke at the time of the study. Most subjects (men, 68.7\%; female, $85.7 \%$ ) had been using tobacco for 1-5 years. A higher percentage of male farm workers consumed alcohol $(74.7 \%)$ than female farm workers (36.1\%; Table I).

TABLE I: SOCIAL AND DEMOGRAPHIC INFORMATION

\begin{tabular}{|c|c|c|c|c|}
\hline \multirow[t]{3}{*}{ Subject characteristics } & \multirow{3}{*}{$\begin{array}{l}\text { Male }(\mathrm{n}= \\
166) \\
\mathrm{n}(\%)\end{array}$} & \multirow{3}{*}{$\begin{array}{l}\text { Female } \\
(\mathrm{n}=108) \\
\mathrm{n}(\%)\end{array}$} & \multicolumn{2}{|l|}{ Total } \\
\hline & & & & \\
\hline & & & $\mathrm{n}$ & $\%$ \\
\hline Age (Yr) Mean (SD) & $30.80(9.46)$ & $\begin{array}{l}32.37 \\
(10.07)\end{array}$ & & \\
\hline Median (Min, Max) & $29(18,60)$ & $\begin{array}{l}30.50 \\
(18,60) \\
\end{array}$ & & \\
\hline Past tobacco use & $88(53.0)$ & $4(3.7)$ & 92 & 33.6 \\
\hline Current tobacco use & $81(48.8)$ & $3(2.8)$ & 84 & 30.7 \\
\hline \multicolumn{5}{|l|}{$\begin{array}{l}\text { Duration of smoking } \\
\text { (Years) }\end{array}$} \\
\hline Mean (SD) & $5.84(4.86)$ & $\begin{array}{l}3.57 \\
(3.36) \\
\end{array}$ & & \\
\hline Median (Min, Max) & $5(1,20)$ & $2(1,10)$ & & \\
\hline \multicolumn{5}{|l|}{$\begin{array}{l}\text { Past and current alcohol } \\
\text { consumption }\end{array}$} \\
\hline Never & $25(15.1)$ & $63(58.3)$ & 88 & 32.1 \\
\hline Quitted & $17(10.2)$ & $6(5.6)$ & 23 & 8.4 \\
\hline Still drinking & $124(74.7)$ & $39(36.1)$ & 163 & 59.5 \\
\hline
\end{tabular}




\begin{tabular}{lllll}
\hline $\begin{array}{l}\text { Amount of alcoholic } \\
\text { drink consumed per } \\
\text { week }\end{array}$ & & & & \\
\hline Occasional & $30(24.2)$ & $26(66.7)$ & 56 & 20.4 \\
\hline 1 glass per week & $17(13.7)$ & $6(15.4)$ & 23 & 8.4 \\
\hline 2-3 glasses per week & $23(18.5)$ & $4(10.3)$ & 27 & 9.9 \\
\hline $\begin{array}{l}\text { More than } 4 \text { glasses } \\
\text { per week }\end{array}$ & $54(43.5)$ & $3(7.7)$ & 57 & 20.8 \\
\hline
\end{tabular}

\section{B. Medical History within the 12 Months before the Study}

Within the 6 months before the study, most farm workers (men, 62.04\%; women, 67.59\%) had a recorded history of illness. In terms of the severity of past health disorders, $70.9 \%$ male and $71.2 \%$ female workers were able to continue working. Moreover, $91.6 \%$ male and $85.2 \%$ female workers had no chronic respiratory system disorder.

\section{Working History}

The main responsibilities of the migrant farm workers in the fruit plantations included picking fruit $(72.3 \%)$, growing fruit $(70.8 \%)$, and carrying a sprayer and spraying pesticides (47.8\%). Three types of fruits (equivalent to $20.4 \%$ of the entire fruit bulk) required pesticide application, including longan $(75.5 \%)$ and durian (64.6\%). In terms of work duration, most workers had been working for $1-5$ years (78.1\%; mean [SD], 4.26 [3.60]). Most migrants worked in plantations smaller than 8 acres $(1$ rai $=0.16$ acres) $(37.6 \%$; 36.74 [47.73] acres).

Regarding the frequency of pesticide spraying, $43.2 \%$ of the migrant farm workers were required to spray pesticides more than three times a week, $39.5 \%$ three times a week, and $13.7 \%$ two times a week (3.74 [1.47]). In terms of the duration of application, $59.9 \%$ of the farm workers spent $6-8$ $\mathrm{h}$ spraying pesticides per session $(6.02[1.73] \mathrm{h})$. The most frequently used pesticide application method involved sprayer cars or motorcycles $(51.1 \%)$. The percentage of workers with exposure to pesticides in the last 24-48 h was $37.6 \%$, whereas $51.5 \%$ were required to be back at work at the fruit farm after spraying pesticides in the last $24-48 \mathrm{~h}$ (Table II).

\section{History of Particle Exposure}

Regarding history of exposure to dust or other chemical particles during work, most migrant farm workers were exposed to pesticides for more than $4 \mathrm{~h}$ per day $(59.9 \%)$ and dust from the fruits $(50.7 \%)$.

\section{E. Use of Personal Preventive Equipment}

The personal preventive equipment used by the migrant workers included long-sleeved shirts $(96.7 \%)$, long pants (96.4\%), and boots $(54.0 \%)$, and $46.7 \%$ used a mask or handkerchief to cover their noses. However, most workers $(89.4 \%)$ did not protect their eyes with goggles (Table III).

\section{F. RSDS}

Approximately $56.2 \%$ of the migrant farm workers exposed to pesticides developed phlegm symptoms. Following pesticide exposure, $55.5 \%$ of participants developed cough, and $47.4 \%$ experienced chest tightness (Table IV).

\section{G. Reactive Paper Assessment of Blood Cholinesterase in Subjects Exposed to Pesticide}

Based on the cholinesterase evaluation of migrant farm workers exposed to pesticide using reactive paper, $52.9 \%$ of the subjects were categorized as being "safe," $23.4 \%$ as "at risk," and $2.2 \%$ as "unsafe."

\begin{tabular}{lcccc}
\multicolumn{4}{c}{ TABLE II: WORK HISTORY } \\
\hline Working History & Male & Female & $\mathrm{n}=274 \quad \%$ \\
\cline { 2 - 3 } & & \\
\hline $\mathrm{n}=166$ & $\mathrm{n}=108$ & \\
\hline
\end{tabular}

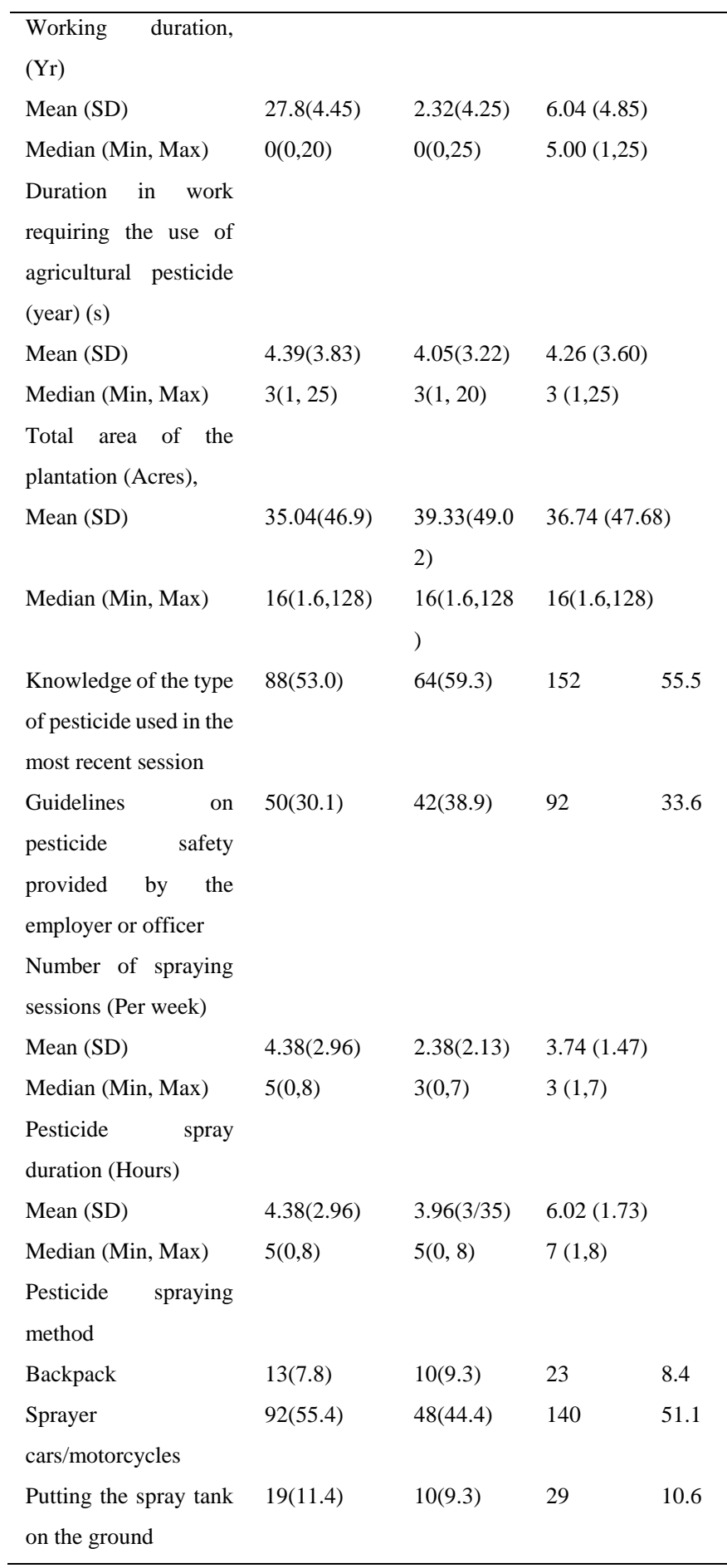

TABLE III: THE USE OF PERSONAL PREVENTIVE EQUIPMENT AND CLOTHING

$\begin{array}{llll}\text { Use of personal } & \text { Yes } & \text { Total } \\ \text { protective equipment } \mathrm{n}= & \text { Male } & \text { Female } & \end{array}$




\begin{tabular}{llll}
\hline 274 & $\mathrm{n}=166$ & $\mathrm{n}=108$ & $\mathrm{n}(\%) \mathrm{N}=274$ \\
\hline $\begin{array}{l}\text { Use of personal } \\
\text { protective equipment }\end{array}$ & & & \\
Eye glasses & $20(12)$ & $9(8.3)$ & $29(10.6)$ \\
Masks to cover the nose & $74(44.6)$ & $54(50)$ & $128(46.7)$ \\
Gloves & $67(44.6)$ & $54(50)$ & $121(44.2)$ \\
Boots & $92(55.4)$ & $56(51.9)$ & $148(54.0)$ \\
Gown to cover the body & $17(10.0)$ & $18(16.7)$ & $35(12.8)$ \\
Others: 1 long-sleeved & $158(95.2)$ & $107(99.1)$ & $265(96.7)$ \\
shirts & & & \\
Long pants & $157(94.6)$ & $107(99.1)$ & $264(96.4)$ \\
\hline
\end{tabular}

TABLE IV: RESPIRATORY SYSTEM SYMPTOM

\begin{tabular}{ll}
\hline Respiratory system symptom & $\begin{array}{l}\text { Total } \\
(\mathrm{n}=274)\end{array}$ \\
\hline Coughing symptoms & $152(55.5)$ \\
Phlegm & $154(56.2)$ \\
Chest tightness & $126(46.0)$ \\
Breathlessness & $112(40.9)$ \\
Chest pain & $130(47.4)$ \\
\hline
\end{tabular}

\section{H. Spirometric Analysis of Lung Function}

Te lung function analysis via spirometry involved measurement of the lung function capacity (\%) in the farm workers. The predicted values (\% predicted) were 92.54 (SD $=17.90)$ for $\mathrm{FEV}_{1}, 88.44(\mathrm{SD}=16.16)$ for $\mathrm{FVC}$, and 89.69 $(\mathrm{SD}=8.36)$ for $\mathrm{FEV}_{1} / \mathrm{FVC}($ Table V).

TABLE V: LUNG FUNCTION ASSESSMENT

\begin{tabular}{|c|c|c|}
\hline \multirow[t]{2}{*}{ Result } & \multicolumn{2}{|c|}{ Lung Function Capacity (\%) } \\
\hline & Mean (SD) & $\begin{array}{l}\text { Median (min, } \\
\text { Max) }\end{array}$ \\
\hline \multicolumn{3}{|l|}{ Predicted value } \\
\hline $\begin{array}{l}\text { FVC } \\
\text { Predicted })\end{array}$ & $88.44(16.16)$ & $\begin{array}{l}88.48 \\
(47.74,149.20)\end{array}$ \\
\hline $\begin{array}{ll}\mathrm{FEV}_{1} & (\% \\
\text { Predicted }) & \end{array}$ & $92.54(17.90)$ & $\begin{array}{l}91.09 \\
(46.0,162.19)\end{array}$ \\
\hline $\begin{array}{l}\text { FEV1/ FVC (\% } \\
\text { Predicted) } \\
\text { Lung function } \\
\text { (L) }\end{array}$ & $89.69(8.36)$ & $\begin{array}{l}90.74 \text { (48.79, } \\
101.04)\end{array}$ \\
\hline FVC & $2.96(.59)$ & $\begin{array}{l}2.95(1.47, \\
4.44)\end{array}$ \\
\hline $\mathrm{FEV}_{1}$ & $2.64(.52)$ & $\begin{array}{l}2.64 \\
3.94)\end{array}$ \\
\hline
\end{tabular}

$\begin{array}{lll}\mathrm{FEV}_{1} / \mathrm{FVC} & 89.69(8.36) & 90.74 \quad(48.79, \\ & & 101.06)\end{array}$

I. Factors Influencing the Respiratory System of Migrant Laborers Exposed to Pesticides

Gender, age, current tobacco use, alcohol consumption, past exposure to dust, and cholinesterase levels in the blood were examined in association with the risk of respiratory system disorders following pesticide exposure. The $\mathrm{FEV}_{1} / \mathrm{FVC}$ ratio was additionally assessed, as it provides an indication of respiratory system impairment.

The odds ratio (OR) (95\% Confidence Interval, CI) obtained for women was 2.787 (1.210 to 6.470), which was higher than that for men. For migrant farm workers who consumed more than four glasses of alcohol per week, the OR $(95 \% \mathrm{CI})$ was calculated as 4.675 (1.395 to 15.671$)$, which was higher than that for workers who consumed lower amounts of alcohol. The OR (95\% CI) for participants exposed to dust for more than $4 \mathrm{~h}$ per day was 2.743 (1.238 to 6.093), which was higher than that for groups with dust exposure for less than $4 \mathrm{~h}$ a day. For the $\mathrm{FEV}_{1} / \mathrm{FVC}$ score, an OR (95\% CI) of 0.95 (0.907 to 0.999$)$ was calculated (Table VI).

\section{J. Factors Underlying Lung Capacity Impairment Caused by Pesticide Exposure in Migrant Laborers}

The multiple linear regression analysis encompassed eight factors related to the FVC score, including gender, age, educational background, history of tobacco use, current alcohol consumption, spraying of pesticides, carrying of a sprayer, and SChE level. Gender, age, carrying of a spray tank, and SChE level were associated with FVC. When other variables were controlled, the eight factors induced changes in the FVC at a moderate level (34\%), with a correlation of $57.9 \%$ and statistical significance of 0.05 .

Significant regression coefficients were obtained for gender, age, carrying of a sprayer, and SChE level. The FVC value was influenced by other variables at a $p$ value of 0.05 . The analysis of the effects of the eight factors based on the correlation coefficient revealed a moderate level of influence (56.2\%). The effect on the $\mathrm{FEV}_{1} / \mathrm{FVC}$ was $31.5 \%$. The regression coefficient data indicated that five factors (gender, age, current alcohol consumption, carrying of a sprayer, and SChE level) were significantly associated with $\mathrm{FEV}_{1}$ changes, controlling for the influence of other variables (Table VII).

TABLE VI: FACTORS ASSOCIATED WITH RESPIRATORY SYSTEM DISORDERS

\begin{tabular}{|c|c|c|c|c|c|c|c|c|}
\hline \multirow[t]{3}{*}{ Factor } & \multirow{3}{*}{$\begin{array}{l}\text { Respiratory } \\
\text { symptoms } \\
\text { No } \\
\text { n }(\%)\end{array}$} & \multirow{3}{*}{$\begin{array}{c}\text { system disorder } \\
\text { Yes } \\
\text { n }(\%)\end{array}$} & \multirow{3}{*}{$\begin{array}{l}\text { Crude } \\
\text { OR }\end{array}$} & \multicolumn{3}{|c|}{ Adjusted } & & \multirow{3}{*}{$\begin{array}{l}\text { Coef. } \\
(\beta)\end{array}$} \\
\hline & & & & $\begin{array}{l}\mathrm{p}- \\
\text { value }\end{array}$ & OR & $95 \% \mathrm{CI}$ & & \\
\hline & & & & & & Lower & Upper & \\
\hline \multicolumn{9}{|l|}{ Gender } \\
\hline Male & $30(63.8)$ & $136(59.9)$ & 1 & 1 & 1 & 1 & 1 & 1 \\
\hline Female & $17(36.2)$ & $9(40.1)$ & 1.181 & .617 & 2.787 & 1.201 & 6.470 & 1.025 \\
\hline \multicolumn{9}{|l|}{ Age (Year) } \\
\hline $18-31$ & $27(54.7)$ & $126(55.5)$ & 1 & 1 & 1 & 1 & 1 & 1 \\
\hline$>31-60$ & $20(42.6)$ & $101(44.5)$ & 1.082 & .087 & .678 & .324 & 1.420 & -.388 \\
\hline \multicolumn{9}{|c|}{ Past and current tobacco use } \\
\hline Not using & $36(76.6)$ & $154(67.8)$ & 1 & 1 & 1 & 1 & 1 & 1 \\
\hline Using & $11(23.4)$ & $73(32.2)$ & 1.551 & 2.39 & 1.452 & .573 & 3.678 & .373 \\
\hline
\end{tabular}




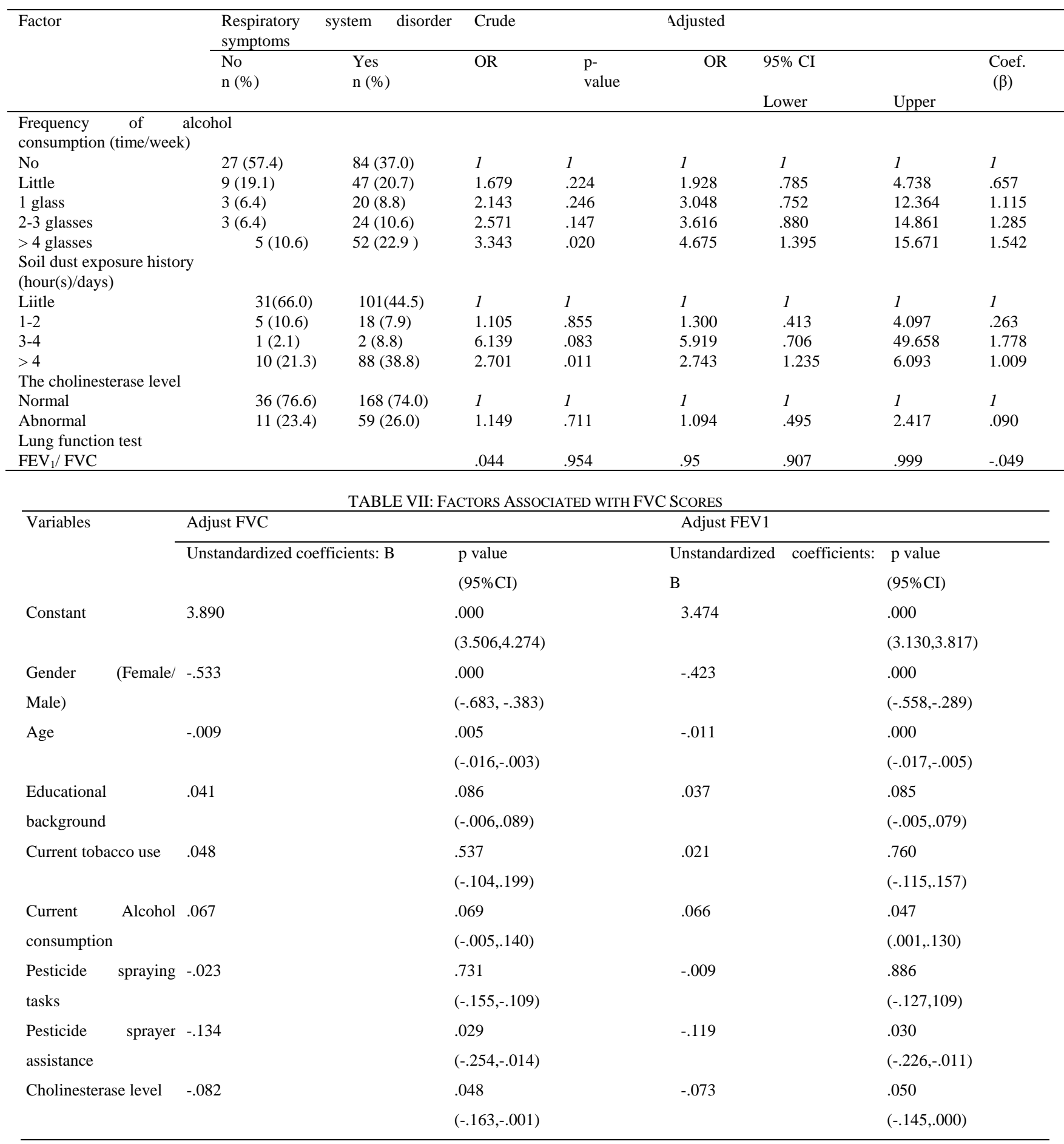

FVC Sig $<0.05 ; \mathrm{R}=0.579 ; \mathrm{R}$ square $=0.335$.

$\mathrm{FEV}_{1} \mathrm{Sig}<05 ; \mathrm{R}=0.562 ; \mathrm{R}$ square $=0.315$

\section{Discussion}

\section{A. Factors Related to Respiratory System Distress Symptoms}

The use of pesticides at work is potentially related to the development of respiratory disorders. Data from our study showed that respiratory ailments are common among workers at farms growing rambutan, durian, longan, and long kong. Overall, 55\% of the migrant farm workers developed cough symptoms, 56.2\% had phlegm, and $46 \%$ had dyspnea, consistent with an earlier study by Hanssen et al. [46], which focused on the prevalence of chronic cough symptoms in Ethiopian farm workers $(43.7 \%)$. The overall difficulty in breathing (70.2\%) corresponded to the findings of a study conducted on workers in vineyards and mango farms, which reported several respiratory disorders, including dyspnea and suffocation crisis $(74.1 \%$ vs. $5.2 \%)$, cough $(27.6 \%$ vs. $15.7 \%)$, expectoration $(25.3 \%$ vs. $13.8 \%)$, and chronic bronchitis (20.7\% vs. $13.9 \%)$ [47].

A multiple logistic regression analysis was used to determine the factors associated with RSDS in migrant farm workers exposed to OP- and CM-containing pesticides. Our experiments showed that the women were at a 2.7 -fold higher risk of developing respiratory illnesses than men (OR [95\% CI]: 2.787 [1.210 to 6.470]. Although only $3.7 \%$ of the women used tobacco, they were naturally more susceptible than the men. Consistent with our findings, earlier studies 
have demonstrated a higher incidence of chronic obstructive pulmonary disease in women than in men [18], [19]. Moreover, a higher prevalence of respiratory system diseases has been reported in women, including asthma [48]. However, these data did not correspond to the results obtained from a cross-sectional study comparing workers who made bottles and those involved in pesticide production, which showed that women are at a lower risk of chronic cough and chest tightness than men [47]. This discrepancy may be caused by the different study patterns. Therefore, the health of female workers should be monitored, even if they do not smoke.

In this study, alcohol consumption was shown to affect the respiratory system. Farm workers who consumed more than four glasses of alcohol per week were associated with a 4.6-times higher risk of developing respiratory disorder symptoms than those who never consumed alcohol (OR [95\% CI]: $4.675[1.395,15.671])$, consistent with the findings of Negatu et al. [15] that a pesticide-exposed group with a history of alcohol consumption developed chronic cough (OR: 3.15 ; 95\% CI: $1.56-6.36)$ and shortness of breath (OR: $6.67 ; 95 \%$ CI: $2.60-17.58$ ) relative to a non-exposed group. However, the study patterns were different between the investigations. While alcohol consumption appeared to be related to the development of respiratory system disorders, no association was evident with tobacco use, although this is a known relevant factor. Therefore, pesticide applicators who drink alcohol should be monitored for respiratory health and should also reduce their alcohol consumption.

Our study showed that the average number of hours of exposure per day was $6 \mathrm{~h}(\mathrm{SD}=1.73)$. The group exposed to dust for more than 4 hours a day had a 2.743-times higher risk than the non-exposed group. Fruit farm plantation workers are more likely to be exposed to soil dust while preparing soil and machinery. However, the degree of exposure varies with the type of work, i.e., mechanical or manual. In this study, the farm workers shared their tasks mutually and were, therefore, exposed to particles containing quartz dust and clay soil. A previous investigation focused on the density of small respirable quartz dust, including that from sand, sandy loam, and clay soil. The density of these soils exceeds the standard set by the American Conference of Governmental Industrial Hygienists. Moreover, soil dust in fruit farms may be contaminated with various types of pesticides. For instance, an earlier study on pesticide density in vineyard soil located near a school in Cape Town, South Africa, identified multiple pesticides, including endosulfan, dimethomorph, penconazole, cyprodinil, boscalid, and bromopropylate [49]. Therefore, the amount of dust in such working areas should be reduced by spraying water on the ground to reduce the exposure to dust in the respiratory tract among migrant workers.

Our experiments did not include an assessment of the dust concentration in the fruit farms under study. Thus, a regular assessment of dust density, which remains to be conducted in Thailand, is recommended. It is necessary to design effective methods to indicate the dust exposure levels of workers and implement measures to control the amount of dust in fruit farms in Thailand to reduce exposure to aerial pesticide particles, which are known to penetrate the respiratory system with adverse effects.

A recent report on the relationship of pesticide exposure with the respiratory system by Ye et al. [50] assessed the effects of exposure to OP- and CM-containing pesticides via an evaluation of the cholinesterase level using reactive paper. Based on the results, $52.9 \%$ of the workers were classified as being "safe," $23.4 \%$ as "at risk," and $2.2 \%$ as "unsafe." However, no significant association was observed with RSDS, in contrast to the findings of a study conducted on farm workers in Ohio, the United States, which indicated that after controlling for variables such as age and use of tobacco, exposure to pesticides is associated with phlegm, wheeze, and flu-like symptoms [51]. Another previous study on farm workers in Iran indicated that pesticide-related tasks are associated with respiratory distress, increasing the risk of developing wheeze and phlegm symptoms [52].

Moreover, our results were inconsistent with those obtained from a cohort of Latin farm workers [26] and a matched case-control study in farm workers in India using OP- and CM-containing pesticides, both of which demonstrated a reduction in red blood cell AChE in association with respiratory disorder symptoms, including runny or stuffy nose, sore throat, dry cough, wheeze, breathlessness, chest tightness, dyspnea, and chronic bronchitis. It is important to note that the assessment patterns of pesticide exposure were different between the studies. A previous study conducted by Chakraborty et al. [16] was a matched case-control and assessment based on erythrocyte AChE using the Ellman method.

Our data did not correspond to those of Hoppin et al. [11], which showed that individuals exposed to pesticides containing dichlorvos and phorate through the use of applicators had 2.48-times the level of wheeze compared to those who did not spray pesticides, after controlling for variables such as age, body mass index (BMI), use of tobacco, asthma, and previous pesticide use. However, this study pattern was different, as it was a prospective investigation that excluded the assessment of SChE in blood.

We assessed SChE levels using the reactive paper test, which is a convenient method in research sites. However, personal factors such as glaucoma or diabetes mellitus often vary during this screening. In this study, the specificities of the test in both the laboratory and field were high $(95.65 \% \mathrm{vs}$. $90.10 \%$ ). Additionally, the accuracy of predictions using a reactive paper in the laboratory and field settings was high (94.59\% vs. $90.38 \%$ ), supporting the applicability of this method for effective SChE screening in the field [29].

The migrant farm workers in our study did not effectively use personal preventive equipment. Overall, $89.4 \%$ did not use goggles, $53.3 \%$ did not wear masks, and 55.8\% did not wear gloves. Moreover, based on our observations and interviews, the safety equipment used did not pass the standard for protection. For instance, the farm workers used hats for protection against sunlight instead of a mask to prevent pesticide inhalation. Personal preventive equipment use was not associated with RSDS, according to a report by Stoecklin-Marois [26], but inconsistent with a study by Thetkathuek et al. [53], which focused on pesticide use by Cambodian farm workers on a vegetable farm. The latter showed a link between the use of personal preventive 
equipment and respiratory, neuronal, and digestive disorder symptoms. One potential explanation for this discrepancy may be differences in the soil types analyzed.

The assessment of the lung function of Cambodian migrant farm workers disclosed an abnormal FEV1/FVC and a low risk of respiratory system disorders. The FEV1 value was in the reference range (OR [95\% CI]: 0.95 [0.097, 0.999]), almost similar to normal FEV1/FVC values. The relationship between FEV1/FVC and the respiratory system was minimal, as it was a reverse causation effect bias caused by the cross-sectional nature of the study, and data collection was conducted only once. It is possible that some workers may have already developed respiratory disorder symptoms before exposure to pesticides or have asymptomatic respiratory disorders.

\section{B. Factors Related to Decreased Lung Function Following Exposure to Pesticides}

The lung function in migrant farm workers exposed to pesticides in Eastern Thailand was assessed using spirometry, including the determination of FVC, FEV, and FEV1/FVC values. Workers in the fruit farm were continuously exposed to a low density of pesticide. The duration of the average work hours was $6.04(4.85) \mathrm{h}$. The occupation hygiene practitioners who conducted the lung function test had completed a master's degree and were trained to use the equipment before performing the test on the migrant farm workers. The researchers had completed the calibration protocol before use on the research site. Three tests were provided to farm workers, and the results were verified based on repeatability criteria. The highest FEV1 (best FEV1) and FVC (best FVC) scores were selected [45], as cited from the Association of Occupational and Environmental Diseases of Thailand [45]. The classification of the lung function disorders was based on the scores of the FVC, FEV1, and FEV1/FVC predicted using the Siriraj Equation [54].

The lung function was normal in most Cambodian migrant farm workers $(65.7 \%)$, whereas $29.2 \%, 4.4 \%$, and $0.7 \%$ had restrictive, obstructive, and mixed abnormalities, respectively.

\section{Factors Related to Decreased FVC from Exposure to Pesticides}

In this study, the multiple linear regression analysis used eight controlled variables: gender, age, educational background, current use of tobacco and alcohol consumption, carrying of a sprayer or assistance with spraying tasks, and SChE level. Gender, age, assisting with pesticide spraying, and SChE were related to the FVC $(p<0.05)$. Women had a lower FVC than men ( $\beta=-0.533$; CI -0.683 to -0.383$)$, consistent with their reported higher susceptibility to respiratory disorders [18], [19]. Data from previous studies consistently suggest that women are more susceptible to such diseases than men, including pulmonary development disorders [17], despite lack of tobacco use [22]. Therefore, in general, the lung function capacity of women appears to be less effective than that of men. The lung size in women is reported to be $10 \%-12 \%$ smaller than that in men of the same age and height [20].

Interestingly, in subjects with an age difference of 1 year, the FVC was reduced by $0.009 \mathrm{~L}$ or $9 \mathrm{~mL}(\beta=-0.009$; $\mathrm{CI}$ :
-0.016 to -0.003$)$ in older subjects, consistent with the theory that aging is related to declining lung capacity [21]. Aging is a significant factor related to greater exposure to pesticides, causing a higher risk of disorders and reduction of FVC. The use of OP- and CM-containing pesticides was associated with FVC in a study conducted on 7-year-old children exposed to dimethyl and total dialkylphosphate. The group reported a significant decrease in lung function, with a lower FVC (L) $(\beta=-0.17,95 \% \mathrm{CI}:-0.34$ to $0.01, p=0.06)$ per 10 -fold increase in the total dialkylphosphate level [55]. The earlier study conducted on 7-year-old subjects estimated lower FVC values than the current study $(170 / 82 \mathrm{~mL})$, which may be attributed to the different age groups and exposure durations.

Table VII shows the significance for the results obtained from individuals assisting with pesticide spraying ("pesticide sprayer assistance" beneath the "pesticide spraying tasks" variable), who had a lower FVC than those who did not assist with pesticide spraying $(0.134 \mathrm{~L}$ or $134 \mathrm{~mL} ; \beta=-0.134$; $\mathrm{CI}$ : -0.254 to -0.014$)$. An abnormal SChE level was associated with a reduced FVC compared with SChE levels within the reference range $(0.082 \mathrm{~L}$ or $82 \mathrm{~mL} ; \beta=-0.082 ; \mathrm{CI}:-0.163$ to $-0.001)$. In a single spray session, one worker usually sprayed the pesticide, and two or three workers assisted with carrying the spray, which led to direct pesticide exposure, especially in cases where the sprayers were positioned in the direction of the wind. Most farm workers $(87.2 \%)$ did not use personal preventive equipment effectively or cover their body for protection $(89.4 \%$ wore no goggles and $53.3 \%$ did not use a mask), corresponding to an earlier report in India showing that farmers and individuals involved in spraying pesticides did not use personal preventive equipment correctly or consider wind direction while spraying or handling the products, leading to a greater risk of associated ailments [25].

Our findings were in agreement with data reported from a study on exposure to pesticides containing OP and CM among farm workers in Sri Lanka by using the Test-Mate system (EQM Research, Ohio) during the spraying season. The FVC scores among these farmers were lower than those of the control group, indicative of restrictive lung dysfunction [13]. However, it must be noted that we used a different method, as our study was a cross-sectional design without the control group and as we applied the reactive paper test to assess the effects of exposure to pesticides in blood.

\section{Factors Related to the Decrease in FEVI from Exposure to Pesticides}

The analysis of lung function based on FEV1 encompassed the abovementioned eight controlled variables. Gender, age, alcohol consumption, carrying of a sprayer, and $\mathrm{SChE}$ were related to changes in FEV1. Women had a lower FEV1 than men $(0.423 \mathrm{~L}$ or $423 \mathrm{~mL} ; \beta=-0.423$; CI: -0.558 to -0.289$)$, and 1 year of age increase was associated with a reduced FEV1 $(0.011 \mathrm{~L}$ or $11 \mathrm{~mL} ; \beta=-0.011$; CI: -0.017 to $-0.005)$. Our data collectively support the theory that the lung function capacity of women is generally lower than that of men, consistent with the 10\%-12\% smaller lung sizes of women than men of the same age and height [19] and higher susceptibility of women to pulmonary disease than men [56]. 
Interestingly, however, the comparison of the impact of using one pack of tobacco per year revealed that lung capacity in a year was reduced by $12.6 \mathrm{~mL}$ in men and $7.2 \mathrm{~mL}$ in women [57].

Alcohol consumption was related to the reduction of FEV1. Those who never consumed alcohol had a lower risk of FEV1 decrease $(0.150 \mathrm{~L}$ or $150 \mathrm{~mL} ; \beta=0.150$; CI: 0.001 to 0.130 ). However, this relationship was not rational, as it was a reverse causation effect bias because of the one-time cross-sectional design of this study. The possibility that the farm workers may have had a previous history of alcohol consumption but that the FEV1 was measured later or did not clearly indicate disorders cannot be discounted. The observed association of alcohol consumption with a reduced FEV1 corresponded to previous results reported by Lange et al. [58], which showed that consumption of $350 \mathrm{~g}$ of alcohol per week reduces FEV1 at the same level as using $15 \mathrm{~g}$ of cigarettes per day.

Individuals assigned the task of carrying a sprayer had a lower FEV1 than those that did not carry a sprayer $(0.119 \mathrm{~L}$ or $119 \mathrm{~mL} ; \beta=-0.119 ; \mathrm{CI}:-0.226$ to -0.011$)$, and an abnormal SChE level was associated with a reduced FEV1, compared with normal levels of SChE $(0.073 \mathrm{~L}$ or $73 \mathrm{~mL} ; \beta=$ -0.073 ; CI: -0.145 to -0.000$)$. Our findings indicate that SChE activity is related to FEV1. The reduction of FEV1 in this study was calculated as $73 \mathrm{~mL} /$ year, which is relatively lower than that reported by de Jong et al. [14]. Their results indicated that the cumulative exposure of Dutch farm workers in the Netherlands is related to a reduced FEV1, especially in those exposed to a high density of pesticides and who use tobacco over the same period $(6.9 \mathrm{~mL} /$ year; $95 \% \mathrm{CI}$ : -10.2 to -3.7$)$.

The significant decrease in the FEV1 detected in this study $(73 \mathrm{~mL})$ was lower than that in farm workers in Ethiopia exposed to a high pesticide density $(140 \mathrm{~mL})$ reported by Negatu et al. [15]. Our results were in accordance to data from a study in Spain involving farm workers who sprayed pesticide over a short period of time. The farm workers had a reduced FEV1 after controlling for age, gender, use of tobacco, weight and height, and alcohol consumption [59]. Our results were also in accordance with a study on farm workers in India showing that exposure to OP- and CM-containing pesticides is associated with a reduction of FVC, FEV1, FEV1/FVC ratio, forced expiratory flow $(25 \%-75 \%)$, and peak expiratory flow rate [16]. In addition, our findings corresponded to a cross-sectional study on pesticide exposure in a mango farm in India disclosing a correlation of reduced lung function with $\mathrm{AChE}$ and butylcholinesterase activities [17].

\section{E. Study Strengths and Limitations}

The main strength of this study was in the site selection. The Cambodian farm workers performed their tasks at the location at which the study was conducted. The study participants were permanent migrant farm workers who grew various types of fruits and used OP- and CM-containing pesticides. Therefore, the evidence obtained on disorders of the respiratory system and lung function was conclusive. Second, the questionnaire used, which was translated from Khmer to Thai and verified by qualified personnel, effectively helped screen for respiratory system distress symptoms.

This study is not without limitations. The main limitation of this study was its cross-sectional design, which could have generated health worker selection bias leading to underestimation of the effects on the respiratory system and lung function. Second, the study was designed to collect data only during the spraying season. Therefore, the AChE level could not be measured, and the respiratory disorder assessment of the sample group was not conducted by a medical physician. Third, the Siriraj equation [54] used to predict lung function was derived from a Thai population rather than a Cambodian population, potentially leading to erroneous predictions of the results, although the physiology of different Asian races is known to be similar. Fourth, the study did not involve sampling for dust density in the workplace. Fifth, translational errors may have occurred during the interview with the sample group. However, to minimize such errors, the researcher had trained the Cambodian interpreter before conducting the interview and was present when the questions were provided to each participant.

\section{Conclusions}

Our study focused on factors related to RSDS and impairment of lung function triggered by exposure to pesticides in migrant farm workers. The main limitations were its cross-sectional design and short time period. Significant variables affecting FVC and FEV1 were determined. Notably, lower FVC and FEV1 scores were associated with the female sex, one year of aging increase, individuals who carried the sprayer, and abnormal levels of SChE. Regarding variables affecting the respiratory system, female sex, consuming over four glasses of alcohol per week, and exposure to dust for longer than $4 \mathrm{~h}$ per day were the most significant. We concluded that exposure to OP- and CM-containing pesticides in agriculture, among other factors, has adverse effects on the respiratory system and lung function. Further longitudinal and retrospective studies are warranted to evaluate the adverse effects of exposure to dust particles from pesticides and dust in the working environment on the respiratory system. The assessment of respiratory system disorders is important for farm workers who are women, drink more than 3 glasses of alcohol/week, are older in age, and perform tasks relating to carrying a sprayer. Moreover, the SChE level should be commonly screened to assess the health of migrant workers.

\section{CONFLICTS OF INTEREST}

All authors declare no conflicts of interest.

\section{AUTHOR CONTRIBUTIONS}

Teerayuth Sa-ngiamsak and Panuwat Choedkiattikool contributed to the analysis of the results and to the writing of the manuscript. All authors discussed the results and contributed to the final manuscript.

\section{REFERENCES}


[1] National Statistical Office Website. (2016). Population and housing census $\quad 2016 . \quad$ year [Online]. Available: http://service.nso.go.th/nso/web/statseries/statseries01.html

[2] National Statistical Office Website. (2016). The direction of labor Thailand. [Online]. Available: http://service.nso.go.th/nso/web/article/article_36.html

[3] Institute for Public Policy Studies Chiang Mai University. (2016). The situation of migrant workers in Thailand. [Online]. Available: http://www.siamintelligence.com/thai-labor-migration-status/

[4] Office of Foreign Workers Administration Website. (2017). Number of foreigners allowed to work across the country. [Online]. Available: https://www.doe.go.th/prd/assets/upload/files/alien_th/a8b24dbc15d4 e304a9db2c2d013fe808.pdf

[5] R. Payán-Rentería, G. Garibay-Chávez, R. Rangel-Ascencio, V. Preciado-Martínez, L. Muñoz-Islas, C. Beltrán-Miranda, S. Mena-Munguía, L. Jave-Suárez, and A. Feria-Velasco, "Effect of chronic pesticide exposure in farm workers of a Mexico community," Arch Environ Occup Health, vol. 67, issue 1, pp. 22-30, 2012.

[6] F. Dorko, J. Danko, S. Flesarova, E. Boros, and A. Sobekova, "Effect of pesticide bendiocarbamate on distribution of acetylcholine-and butyrylcholine-positive nerves in rabbit's thymus," Eur J Histochem, vol. 55, pp. 206-209, 2011.

[7] P. Kachaiyaphum, N. Howteerakul, D. Sujirarat, S. Sukhontha, and N. Suwannapong, "Serum cholinesterase levels of Thai chilli-farm workers exposed to chemical pesticide: prevalence estimates and associated factors," J Occup Health, vol. 52, issue 1, pp. 89-98, 2010.

[8] H. K. Jensen, F. Konradsen, E. Jørs, J. H. Petersen, and A. Dalsgaard, "Pesticide use and self-reported symptoms of acute pesticide poisoning among aquatic farmers in Phnom Penh," Cambodia. J Toxicol, vol. 2011, 2011.

[9] R. Kamanyire and L. Karalliedde, "Organophosphate toxicity and occupational exposure,” Occup Med (Lond.), vol. 54, issue 2, pp. 69-75, 2004.

[10] A. Yassi, T. Kjellstrom, T. K. Kok, and T. L. Gudotli, "Basic Environmental Health," World Health Organization, London, U.K.: Oxford University Press, 2001.

[11] J. A. Hoppin, D. M. Umbach, S. J. London, C. F. Lynch, M. C. Alavanja, and D. P. Sandler, "Pesticides associated with wheeze among commercial pesticide applicators in the agricultural health study," Am J Epidemiol, vol. 163, issue 12, pp. 1129-37, 2006.

[12] L. Karalliedde, M. Eddleston, and V. Murray, "The global picture of organophosphate insecticide poisoning," Organophosphates and Health, London: Imperial College Press, 2001.

[13] R. J. Peiris-John, D. K. Ruberu, A. R. Wickremasinghe, and W. van-der-Hoek, "Low-level exposure to organophosphate pesticides leads to restrictive lung dysfunction," Respir Med, vol. 99, issue 10, pp 1319-1324, 2005.

[14] K. Jong, H. M. Boezen, H. Kromhout, R. Vermeulen, D. S. Postma, and J. M. Vonk, "Cohort study. Pesticides and other occupational exposures are associated with airway obstruction: the LifeLines cohort study," Occup Environ Med, vol. 71, pp. 88-96, 2014.

[15] B. Negatu, H. Kromhout, Y. Mekonnen, and R. Vermeulen, "Occupational pesticide exposure and respiratory health: A large-scale cross-sectional study in three commercial farming systems in Ethiopia," Thorax, vol. 72, issue 6, pp. 498-499, 2017.

[16] S. Chakrabotry, S. Mukherjee, S. Roychoudhury, S. Siqqique, T. Lahiri, and M. R. Ray, "Chronic exposure to cholinesterase-inhibiting pesticides adversely affect respiratory health of agricultural workers in India Department of experimental hematology," Journal of Occupational Health, vol. 51, issue 6, pp. 488-497, 2009.

[17] M. Fareed, M. K. Pathak, V. Bihari, R. Kamal, A. K. Srivastava, and C. N. Kesavachandran, "Adverse respiratory health and hematological alterations among agricultural workers occupationally exposed to organophosphate pesticides: A cross-sectional study in North India," PLoS ONE, vol. 8, issue 7, p. e69755, 2013.

[18] P. Carrasco-Garrido, J. Miguel-Díez, J. Rejas-Gutierrez, A. Martín-Centeno, E. Gobartt-Vázquez, V. Hernandez-Barrera, A. G. Miguel, and R. Jimenez-Garcia, "Characteristics of chronic Obstructive pulmonary disease in Spain from a gender perspective," BMC Pulmonary Medicine, vol. 9, no. 2, 2009.

[19] E. K. Silverman, S. T. Weiss, J. M. Drazen, H. A. Chapman, V. Carey, E. J. Campbell, P. Denish, R. A. Silverman, J. C. Celedon, J. J. Reilly, L. C. Ginns, and F. E. Speizer, "Gender-related differences in severe, early-onset chronic obstructive pulmonary disease," American Journal of Respiratory and Critical Care Medicine, vol. 162, issue 6, pp. 2152-2158, 2000.
[20] F. Bellemare, A. Jeanneret, and J. Couture, "Sex differences in thoracic dimensions and configuration," Am J Respir Crit Care Med., vol. 168, issue 3, pp. 305-312, 2003.

[21] E. Sillanpaa, L. Stenroth, A. Y. Bijlsma, T. Rantanen, J. S. McPhee, T. M. Maden-Wilkinson, M. V. J. Narici, H. Gapeyeva, M. Paasuke, Y. Barnouin, J. Y. Hogrel, G. S. Butler-Browne, C. G. Meskers, A. B. Maier, T. Tormakangas, and S. Sipila, "Associations between muscle strength, spirometric pulmonary function and mobility in healthy older adults," Age, vol. 36, p. 9667, 2014.

[22] X. Wu, K. Reynolds, X. Duan, X. Xi, R. F. Reynolds, P. K. Whelton, and J. He, "Cigarette smoking and exposure to environmental tobacco smoke in China: The International collaborative study of cardiovascular disease in Asia," Am J Public Health, vol. 94, pp. 1972-1976, 2004.

[23] R. Magauzi, B. Mabaera, S. Rusakaniko, A. Chimusoro, N. Ndlovu, M. Tshimanga, G. Shambira, A. Chadambuka, and A. Gombe, "Health effects of agrochemicals among farm workers in commercial farms of Kwekwe district, Zimbabwe," Pan Afr. Med. J., vol. 9, p. 26, 2011.

[24] K. Atreya, B. K. Sitaula, H. Overgaard, R. M. Bajracharya, and S Sharma, "Knowledge, attitude and practices of pesticide use and acetylcholinesterase depression among farm workers in Nepal," Int $J$ Environ. Health Res., vol. 22, no. 5, pp. 401-415, 2012.

[25] B. Singh and M. K. Gupta, "Pattern of use of personal protective equipments and measures during application of pesticides by agricultural workers in a rural area of Ahmednagar district, India,' Indian J. Occup. Environ. Med., vol. 13, issue 3, pp. 127-130, 2009.

[26] M. T. Stoecklin-Marois, C. W. Bigham, D. Bennett, D. J. Tancredi, and M. B. Schenker, "Occupational exposures and migration factors associated with respiratory health in California Latino farm workers: the MICASA study," Journal of Occupational and Environmental Medicine, vol. 57, issue 2, pp. 152-158, 2015.

[27] A. Suryahadi, A. Morgan, E. J. Soto, and Z. Dettrick, "Economic growth and poverty reduction in Indonesia before and after the Asian financial crisis," Bulletin of Indonesian Economic Studies, vol. 48, issue 2, pp. 209-227, 2012.

[28] N. Mucci, G. Giorgi, M. Roncaioli, J. F. Perez, and G. Arcangeli, "The correlation between stress and economic crisis: a systematic review,' Neuropsychiatr. Dis. Treat., vol. 12, pp. 983-993, 2016.

[29] A. Thetkathuek, P. Yenjai, W. Jaidee, P. Jaidee, and P. Sriprapat, "Pesticide exposure and cholinesterase levels in migrant farm workers in Thailand," J Agromedicine, vol. 22, issue 2, pp. 118-130, 2017.

[30] B. H. Woollen, "Biological monitoring for pesticide absorption," Ann. Occup. Hyg., vol. 37, pp. 525-540, 1993.

[31] L. Karalliedde and N. Senanayake, "Organophosphorus insecticide poisoning,” Br. J. Anaesth., vol. 63, pp. 736-750, 1990.

[32] C. Lu, L. C. Anderson, and R. A. Fenske, "Determination of atrazine levels in whole saliva and plasma in rats: Potential of salivary monitoring for occupational exposure," J. Toxicol. Environ. Health, vol. 50, pp. 101-111, 1997.

[33] V. How, Z. Hashim, P. Ismail, M. D. Said, P. Omar, and S. B. Mohd, "Exploring cancer development in adulthood: cholinesterase depression and genotoxic effect from chronic exposure to organophosphate pesticides among rural farm children," $J$ Agromedicine, vol. 19, issue 1, pp. 35-43, 2014

[34] J. N. Hofmann, A. Carden, R. A. Fenske, H. E. Ruars, and M. C. Keifer, "Evaluation of a clinic-based cholinesterase test kit for the Washington State Cholinesterase Monitoring Program," Am. J. Ind. Med., vol. 51, issue 7, pp. 532-538, 2008

[35] G. Rodríguez-Fuentes and G. Gold-Bouchot, "Environmental monitoring using acetylcholinesterase inhibition in vitro. A case study in two Mexican lagoons," Mar. Environ. Res., vol. 50, issues 1-5, pp. 357-360, 2000.

[36] Migrant Workers and Health. (2016). Ministry of Labor Website. [Online]. Available: http://www.ilo.org/dyn/migpractice/docs/176/Health.pdf

[37] Notification of the Ministry of Public Health on Health Check-up and Health Insurance for Foreign Workers. (2015). Ministry of Public health Website. [Online]. Available: http://phdb.moph.go.th/phdb/admin/files

[38] Z. Sutoluk, Z. Kekec, N. Daglioglu, and I. Hant, "Association of chronic pesticide exposure with serum cholinesterase levels and pulmonary functions," Arch Environ. Occup. Health., vol. 66, issue 2, pp. 95-99, 2011.

[39] M. K. Pathak, M. Fareed, A. Srivastava, B. S. Kangtey, V. Bihari, M. Kuddus, and C. Kesavachandran, "Seasonal variations in cholinesterase activity, nerve conduction velocity and lung function among sprayers exposed to mixture of pesticides," Environ. Sci. Pollut. Res. Int., vol. 20, issue 10, pp. 7296-300, 2013. 
[40] F. Y. Hsieh, D. A. Bloch, and M. D. Larsen, "A simple method of sample size calculation for linear and logistic regression," Statistics in Medicine, vol. 17, issue 14, pp. 1623-1634, 1998.

[41] S. Prosongwattanas, S. J. Maruo, O. Panpakde, and S. Kalampakorn, "Respiratory symptom and pulmonary function of home based garment workers: A case study in Bansang community, Bangpa-in district, Phra NaKhon Si Ayitthaya province," Journal of Public Health Nursing, vol 24, issue 2, pp. 33-47, 2010.

[42] Bureau of Occupational and Environmental Diseases, Department of Disease Control, Ministry of Public Health Thailand, Guide to Occupational Health Services for Public Health Officials: Health Clinics for Agricultural Farmers, Bangkok: Agricultural Cooperative Federation of Thailand Company, 2012.

[43] C. Husbumrer, T. Rochanachin, C. Punpeng, C. Bumpenyu, and S. Sinlapanapaporn, "The development of reactive paper for the screening test of early organophosphorus and some carbamates insecticides poisoning in the fieldwork," Ministry of Public Health, Bangkok, 1985.

[44] Guideline for spirometry evaluation of Thoracic Society of Thailand under Royal Patronage. (2016). Summacheeva Website. [Online]. Available:

http://www.summacheeva.org/documents/book_spirometry.pdf

[45] Guideline for Standardization and Interpretation of Pulmonary Function Test by Spirometry in Occupational Health Setting. (2017). The Association of Occupational and Environmental Diseases of Thailand Website. [Online]. Available: http://www.summacheeva.org/documents/book_spirometry.pdf

[46] V. M. Hanssen, A. W. Nigatu, Z. K. Zeleke, B. E. Moen, and M. Bråtveit, "High prevalence of respiratory and dermal symptoms among ethiopian flower farm workers," Arch Environ. Occup. Health, vol. 70, issue 4, pp. 204-213, 2015.

[47] E. Zuskin, J. Mustajbegovic, E. N. Schachter, J. Kern, and D. Pavicic, "Respiratory function in vineyard and orchard workers," Am. J. Ind. Med., vol. 3, pp. 250-255, 1997.

[48] L. Rhodes, J. E. Moorman, and S. C. Redd, "Sex differences in asthma prevalence and other disease characteristics in eight states," J. Asthma., vol. 42, pp. 777-782, 2005.

[49] A. J. Swanepoel, H. Kromhout, Z. A. Jinnah, L. Portengen, K. Renton, K. Gardiner, and D. Rees, "Respirable dust and quartz exposure from three South African farms with sandy, sandy loam, and clay soils," Ann. Occup. Hyg., vol. 55, issue 6, pp. 634-643, 2011.

[50] M. Ye, J. Beach, J. W. Martin, and A. Senthilselvan, "Pesticide exposures and respiratory health in general populations," J. Environ Sci. (China), vol. 51, pp. 361-370, 2017.

[51] N. L. Sprince, M. Q. Lewis, P. S. Whitten, S. J. Reynolds, and C. Zwerling, "Respiratory symptoms: associations with pesticides, silos, and animal confinement in the Iowa Farm Family Health and Hazard Surveillance Project" Am. J. Ind. Med., vol. 38, issue 4, pp. 455-462, 2000.

[52] N. Hashemi, M. Mirsadraee, M. T. Shakeri, and A. R. Varasteh, "Prevalence of work-related respiratory symptoms in Iranian farmers," Can. Respir. J., vol. 13, issue 4, pp. 198-202, 2006.

[53] A. Thetkathuek, N. Suybros, W. Daniell, P. Meepradit, and W. Jaidee, "Factors influencing poisoning symptoms: A case study of vegetable farmers exposed to mixed insecticides in Prek Balatchheng village, Cambodia," J. Agromedicine, vol. 19, issue 4, pp. 337-345, 2014.

[54] W. Dejsomritrutai, P. Wongsurakiat, N. Chierakul, S Charoenratanakul, A. Nana, and K. N. Maranetra, "Comparison between specified percentage and fifth percentile criteria for Spirometry interpretation in Thai patients," Respirology, vol. 7, issue 2, pp. 123-127, 2002.

[55] R. Raanan, J. R. Balmes, K. G. Harley, R. B. Gunier, S. Magzamen, A. Bradman, and B. Eskenazi, "Decreased lung function in 7-year-old children with early-life organophosphate exposure," Thorax, vol. 71, issue 2, pp. 148-153, 2016,

[56] A. C. Michelle, W. C. Jeffrey, W. V. James, J. Samuel, J. R. Arbes, R. Dori, K. S. Germolec, and D. C. Korach, "It's all about sex: Male-female differences in lung development and disease. Trends Endocrinol Metab," Trends Endocrinol. Metab., vol. 18, issue 8, pp. 308-313, 2007.

[57] X. Xu, D. W. Dockery, J. H. Ware, F. E. Speizer, and B. G. Ferris, "Effects of cigarette smoking on rate of loss of pulmonary function in adults: a longitudinal assessment," Am. Rev. Respir. Dis., vol. 146, issue 5, pp. 1345-1348, 1992.
[58] P. Lange, S. Groth, J. Mortensen, M. Appleyard, J. Nyboe, G. Jensen, and P. Schnohr, "Pulmonary function is influenced by heavy alcohol consumption," Am. Rev. Dis., vol. 137, issue 5, pp. 119-123, 1988.

[59] A. F. Hernández, I. Casado, G. Pena, F. Gil, E. Villanuev, and A. Pla, "Low level of exposure to pesticides leads to lung dysfunction in occupationally exposed subjects," Inhal. Toxicol., vol. 20, pp. 839-849, 2008 .

Copyright $\odot 2020$ by the authors. This is an open access article distributed under the Creative Commons Attribution License which permits unrestricted use, distribution, and reproduction in any medium, provided the original work is properly cited (CC BY 4.0).

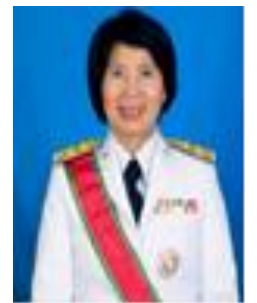

A. Thetkathuek was born in city of Buriram, Thailand, on July 12 , 1964. She obtained the Ph.D. (Trop. Med) in branch of environmental toxicology, Faculty of Tropical Medicine, Mahidol University, Thailand-2005; the master of public health in environmental Health, Faculty of Public Health, Khonkaen University, Thailand-1994; the degree of bachelor of nursing, Faculty of Nursing, Khonkaen University, Thailand-1987.

She is working as the associated professor attached to the Department of Industrial Hygiene \& Safety, Faculty of Public health, Burapha university. Her current research interests are on occupational health, toxicology, and health risk assessment. Her interesting publications are as follows: 1) Thetkathuek, A., Jaidee, W. \& Jaidee, P. (2018). Factors that contribute to insecticide poisoning among immigrant agricultural workers in Thailand. International Journal of Occupational and Environmental Health, 23 (1): 60-70. 2) Thetkathuek, A., Meepradit, P. \& Sa-ngiamsak, T. (2017). A cross-sectional study of musculoskeletal symptoms and risk factors in Cambodian fruit farm workers in eastern region, Thailand. Journal of Safety and health at work. https://doi.org/10.1016/j.shaw.2017.06.009. Online publication on June 1 2017. Estimated publication on March 1 2018. 3) Thetkathuek, A., Jaidee, W. \& Jaidee, P. (2017). Access to Health Care by Migrant Farm Workers on Fruit Plantations in Eastern Thailand $\mathbf{J}$ Agromedicine, 22(3), 189-199. She has authored more than 40 research papers and guided $2 \mathrm{Ph}$.D. students and 18 MS.C. of occupational health students. She has also written 11 books on occupational health and safety, health risk assessment, health impact assessment.

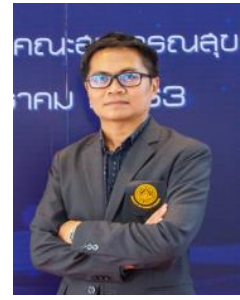

Teerayut Sa-ngiamsak was born in city of Buriram, Thailand, on Jan 22, 1978. He graduated with doctor's degree in occupational safety and health, University of Porto, Portugal-2016, his master degree in electrical Engineering, Faculty of engineering, Ladkrabang University, Thailand-2006 and his bachelor degree in Electrical power Engineering, Faculty of engineering, Mahanakorn University, Thailand-2000. He is currently working as an assistant professor in the Department of Industrial Hygiene \& Safety, Faculty of Public health, Burapha university, Thailand. His research interest is in Industrial Safety Engineering Control, Human Factors, EMG investigation, Industrial Ventilation Control. He has authored more than 10 research papers and having been supervisor for 5 M.SC. students in occupational health and safety so far. He has also written one book on Principle of Industrial Engineering for Safety officers.

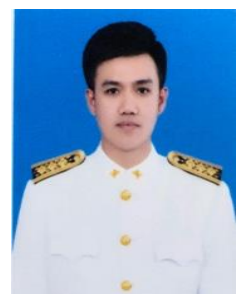

Panuwat Choedkiattikool was born in Chanthaburi, Thailand, on June 18, 1992. He obtained the master of science program (occupational health and safety), Burapha University, Thailand, 2017. He is working as a public health technical officer at the Health Promoting Hospital. Some of his interesting publications are as follows: 1) Program for safety behavior modification to prevent the risk exposure of organophosphate and carbamate insecticides among fruit farmers in Chanthaburi, Thailand (9th ICPH-GMS, 2017), in Yangon, Myanmar 2) Factors Affecting Safety behavior to Prevent the Risk Exposure of Organophosphate and Carbamate Insecticides among Fruit Farmers in Kaeng Hang Maeo District, Chanthaburi Province Proceeding of $10^{\text {th }}$ Rajamangala University of Technology Tawan-ok Research Conference, 2017. 